\title{
Assessment of risk factors for Non-Communicable diseases among a cohort of community health workers in Western Cape, South Africa
}

\author{
1. University of the Western Cape, Physiotherapy \\ 2. University of Missouri, Health Physiotherapy \\ 3. University of Western Cape, Faculty of Community and Health Sciences
}

Levona Johnson ${ }^{1}$, Laura Schopp ${ }^{2}$, Firdouza Waggie ${ }^{3}$, J.M Frantz ${ }^{3}$

Correspondence: Levona Johnson (Levona.Johnson@westerncape.gov.za))

\section{Introduction}

Community Health Workers (CHWs) have been identified as the key health professionals to drive the agenda of the prevention of health risk behaviours, linked to noncommunicable diseases (NCDs) in South Africa. They are regarded as the agents of change, who will provide impetus to the achievement of the health behaviour goals, set out by the South African National Department of Health ${ }^{1}$. However, this cohort, may suffer from an array of NCDs. There are various risk factors that influence the health of individuals and contribute to NCDs, including modifiable and non-modifiable risk factors, which cannot be changed, or altered by an intervention, such as age, family history, gender and ethnicity ${ }^{2,3}$. Modifiable risk factors have been classified as behavioural, physical, and biological ${ }^{4}$.

Globally, NCDs are responsible for $80 \%$ of premature deaths in $\mathrm{LMICs}^{5,6}$. In response to the NCD pandemic, the World Health Organisation (WHO) set a global target in 2012, which was aimed at reducing premature deaths, caused by NCDs, by $25 \%$, by the year $2025^{7}$. However, this goal will require drastic, immediate, and targeted approaches that address the root causes of NCDs. South Africa has followed the global trend, and evidence depicts an increase in $\mathrm{NCDs}^{8}$, with a $27 \%$ probability of dying between the ages of 30 and 70 years, as a result of cardiovascular diseases (CVDs), diabetes, cancers, or chronic respiratory conditions ${ }^{7,9}$. This is similar to other countries such as India (26\%), Philippines (28\%), Democratic People's Republic of Korea (27\%), Mali (26\%), Russian Federation (30\%), Ukraine (28\%), Tajikistan (29\%), Fiji (31\%), Afghanistan (31\%) and Armenia (31\%) In the Western Cape, the prevalence of chronic diseases of lifestyle raises major concerns about the communities' health risk behaviour. The Burden of Disease Survey for the Western Cape, which was released on 24 April 2017, reported that NCDs contributed to $61 \%$ of deaths in the Western Province ${ }^{10}$.

The top 6 leading risk factors contributing to the global burden of NCDs, are reported as high blood pressure (13\%), tobacco use $(9 \%)$, increased blood glucose levels $(6 \%)$, physical inactivity $(6 \%)$, harmful consumption of alcohol (5.9\%) and obesity/overweight (5\%) $)^{9,11}$. In South Africa, the 4 top modifiable risk factors that influence the burden of disease are unhealthy diets, smoking, physical inactivity and the harmful use of alcohol, especially in citizens living in urban areas ${ }^{5,12}$
In addition, studies have revealed that the prevalence of NCDs, such as cardiovascular disease, diabetes, and hypertension, among healthcare workers are similar to the general population, and could be attributed to lifestyle choices ${ }^{13,14,15}$. Evidently, health care workers do not practice what they preach, and instead have unhealthy health behaviours, such as smoking, physical inactivity, consumption of alcohol, eating junk food, obesity and sleeping erratically ${ }^{16}$. These behaviours clearly predispose them to NCDs. In addition to modifiable risk factors for NCDs, non-professional healthcare workers (those without formal and/or tertiary education) (20.3\%) reported a higher HIV prevalence, than professional health care workers $(13.7 \%)^{17}$. Current studies have also reported that asthma is more prevalent in health care workers, than in non-health care workers ${ }^{18}$. In addition, workplace exposure, which includes stress, physical exertion, exposure to disinfectants, aerolised drugs, powered gloves, second-hand smoke \& allergens could cause asthma in previously healthy individuals ${ }^{18}$.

Communities may lack the understanding about the impact of NCDs, especially regarding perceived susceptibility and perceived severity ${ }^{19}$. Since $\mathrm{CHWs}$ originate from the communities in which they work ${ }^{20}$, it is assumed that they, consequently, will have similar misconceptions about the full impact of $\mathrm{NCDs}^{19}$ on their quality of life, and demonstrate similar health risk behaviours as these communities. It is perceived that, in order for health professionals to deliver accurate and effective service, they have to be good role models and understand their own health behaviours ${ }^{21,22}$. Studies suggest that CHWs lack sufficient knowledge about NCDs and the risk factors ${ }^{23}$, therefore, empowering the CHWS with this knowledge would help them to identify and address it in their own lives, and communicate this insight during their health engagements with the communities. As CHWs are afforded the means to improve their own healthcare, it is assumed that they would transfer the new skill sets and health behaviours to the communities, by modelling their newly-adopted lifestyles to them. Once communities are empowered, there could be an increase in the sense of self-determination and self-efficacy ${ }^{24}$. The snowballing effect, or social persuasion effect, would promote healthy behaviours, and decrease the health risk behaviours in the communities, which could result in a continuum of the empowering process ${ }^{25}$. In order to train the trainer in health care for self, and simultaneously equip him/her to transfer 
these self-management skills to others, an understanding of their perceived risk factors is required. Therefore, this current study is aimed at assessing the risk factors of NCD prevalence among CHWs in urban and rural areas.

\section{Methodology}

This article forms part of a larger study that explored the empowering of CHWs, to improve their health behaviours, using a self-management approach. A quantitative survey design was employed for the aspect of the study that this article is based on. This method is useful when data on individuals' personal thoughts, behaviours, and feelings are sought ${ }^{26}$, therefore, it was applicable to this current study that explored the perceptions of CHWs.

The study was conducted in two communities of the Western Cape province of South Africa, purposively selected, because of their need for active CHWs to work in the area. Genandendal and Greyton were selected for the rural area, while Lavender Hill and the Retreat area were considered for the urban area. Both the urban and rural areas are classified as low socio-economic and are inhabited by predominately persons racially profiled as 'coloured'. The Lavender Hill and Retreat areas are ridden with violence. Due to the scarcity of qualified tertiary-trained medical professionals the CHWs in Genadendal \& Greyton act as first responders for these towns.

The population for this current study included, approximately, 3400 CHWs. The study focused on those working in the selected areas which employs approximately 200 CHWs. All of them were targeted to participate in the study but only 154 agreed to participate.

In recent years there has been an increased political support for CHWs in South Africa. With the focus placed on reengineering primary health care, it was determined that CHWs should be arranged into nurse-lead teams ${ }^{27}$ and be employed by NGOs identified and funded by the provincial health departments ${ }^{28}$. The roles of CHWs in South Africa are concentrated in the domains of prevention and promotion at both household and community levels. They are predominately lay health workers who have received informal job training and have no professional or tertiary training ${ }^{21}$.

By means of the convenient sampling technique, a sample of $154 \mathrm{CHWs}$, from four Non-governmental organisations (NGOs), were selected for this study. As this was a pre-test post-test design, generalisability of results is not the focus of the study but the effect on the group and thus the sample size was considered large enough. A questionnaire ${ }^{29}$, was employed in the data collection process. The questionnaire was based on questions from various tools, namely, the Short Form 12 (SF-12), the Health Promoting Lifestyle Profile 11 (HPLP-11), while an additional section, comprising health status and bio-demographics were included, as well. HPLPII has 52 items, with responses including $1=$ never, $2=$ Sometimes, 3 = Often, and $4=$ Routinely. The SF-12 has been used extensively in the general population ${ }^{30}$, as well as in studies with disease groups ${ }^{31}$. In addition, the reliability of the tool was further tested across various cultures ${ }^{32}$. The HPLP11 questionnaire is a 52-item, self-reported questionnaire that employs a 4-point Likert-type scale, to determine the frequency that respondents participate in health behaviours. It has been widely used in research on health behaviour, and has demonstrated high construct reliability, internal consistency, and test-retest reliability ${ }^{33}$. The subscale total scores were derived by generating the mean of items within those subscales (Health Responsibility, Physical Activity, Nutrition, Spiritual Growth, Interpersonal Relationships and Stress Management). The mean score can range from 1 (low participation) to 4 (high participation) for each subscale, with each subscale composed of different numbers of items. Total scores were used in the data analysis to minimize risk of Type I error, as analyses using individual variables would inflate the number of analyses and thereby risk reporting a significant relationship between variables where no such relationship exists.

The researcher (LJ) contacted the head of the NGOs and explained the purpose of the study. CHWs were then invited to a meeting, where the study was outlined, and all the CHWs were invited to participate in this current study. Those who were willing to participate in the study received an information sheet, and signed a consent form before completing the questionnaire. The questionnaires were available in both English and Afrikaans, which allowed the respondents to complete the questionnaires in their language of choice. The questionnaires were administered by the researcher (LJ), and was completed in the presence of the researcher (LJ), to allow the respondents to receive clarity to questions that might have arisen.

Data analyses were done in consultation with a statistics coach. Descriptive, as well as inferential statistics were conducted. Descriptive statistics were used to summarise the urban and rural information of the CHWs, in the form of means, standard deviations, ranges, and t-tests, to ascertain whether urban and rural CHWs differed on any of the measures of interest. The measure is not on a nominal scale, the responses are 1-4 (an interval scale) and verbal descriptor anchor points were added to the numeric scale for clarity. The SPSS was used to analyse the data. Fishersexact test was used to examine possible associations between socio-demographic characteristics and behaviour status. A significance level of $0.05(5 \%)$ was used for the test.

Ethical clearance was obtained from the Humanities and Social Science Research Ethics Committee of the University of the Western Cape (HS/17/8/23), and permission was received from the boards of the relevant NGOS that employed the CHWs. Written informed consent was obtained from all respondents and confidentiality was ensured.

\section{Results}

\section{Demographics}

Of the 154 respondents, 10 were male and 144, female, with a mean age of 42.2 years $(S D=10.9)$. The socio-demographic status indicated that $90 \%$ had an education level below grade 12. In addition, the mean years of working experience was 4.5 years. The health status of the respondents in this current study are depicted in Table 1 . The associations between the gender and medical conditions of the respondents were not statistically significant. The relatively small sample size, and the unevenness in the values within many of the variables (for instance, 93.6\% of respondents were females), could be a reason that the associations between the respondents' gender and their medical conditions, were not statistically significant. Approximately $30 \%$ of the respondents smoked, had high blood pressure, and participated in less than 3 days of physical activity.

Based on the health need questionnaire, the behaviour of the respondents, and the risk factors that could contribute to NCDs, are described in Tables 2-7. The mean for each question was determined, as well as the mode. The overall mode for health responsibility was 3, for physical activity, it 
Table 1: Health status of participants

\begin{tabular}{|c|c|c|c|c|}
\hline VARIABLE & TOTAL & MALE & FEMALE & P-VALUE \\
\hline $\begin{array}{l}\text { Physical Activity } \\
\text { Physically active for } 30 \text { minutes } \square 3 \text { days } \\
\text { Physically active for } 30 \text { minutes } \square 3 \text { days }\end{array}$ & $\begin{array}{l}52(33.8) \\
102(66.2)\end{array}$ & $\begin{array}{l}4(40.0) \\
6(60.0)\end{array}$ & $\begin{array}{l}48(33.3) \\
96(66.7)\end{array}$ & 0.734 \\
\hline $\begin{array}{l}\text { Tobacco use } \\
\text { - YES (Current use of tobacco products) } \\
\text { - No (No tobacco products used) }\end{array}$ & $\begin{array}{l}55(36.2) \\
97(63.8)\end{array}$ & $\begin{array}{l}3(30.0) \\
7(70.0)\end{array}$ & $\begin{array}{l}52(36.6) \\
90(63.4)\end{array}$ & 1.000 \\
\hline $\begin{array}{l}\text { High Blood Pressure } \\
\text { YES } \\
\text { NO }\end{array}$ & $\begin{array}{l}46(30.1) \\
107(69.9)\end{array}$ & $\begin{array}{l}3(30.0) \\
7(70.0)\end{array}$ & $\begin{array}{l}43(30.1) \\
100(69.9)\end{array}$ & 1.000 \\
\hline $\begin{array}{l}\text { High Cholesterol } \\
\text { YES } \\
\text { NO }\end{array}$ & $\begin{array}{l}17(11.0) \\
137(89.0)\end{array}$ & $\begin{array}{l}1(10.0) \\
9(90.0) \\
\end{array}$ & $\begin{array}{l}16(11.1) \\
128(88.9)\end{array}$ & 1.000 \\
\hline $\begin{array}{l}\text { Heart Attack } \\
\text { YES } \\
\text { NO }\end{array}$ & $\begin{array}{l}2(1.3) \\
152(98.7)\end{array}$ & $\begin{array}{l}1(10.0) \\
9(90.0)\end{array}$ & $\begin{array}{l}1(0.7) \\
143(99.3)\end{array}$ & 0.126 \\
\hline $\begin{array}{l}\text { Diabetes } \\
\text { YES } \\
\text { NO }\end{array}$ & $\begin{array}{l}17(11.1) \\
136(89.9)\end{array}$ & $\begin{array}{l}1(10.0) \\
9(90.0) \\
\end{array}$ & $\begin{array}{l}16(11.2) \\
127(88.8)\end{array}$ & 1.000 \\
\hline $\begin{array}{l}\text { High Blood Sugar (Not on medication) } \\
\text { YES } \\
\text { NO }\end{array}$ & $\begin{array}{l}5(3.3) \\
148(96.7)\end{array}$ & $\begin{array}{l}0(0.0) \\
10(100)\end{array}$ & $\begin{array}{l}5(3.5) \\
138(96.5)\end{array}$ & 1.000 \\
\hline $\begin{array}{l}\text { Depression } \\
\text { YES } \\
\text { NO }\end{array}$ & $\begin{array}{l}11(7.1) \\
143(92.9)\end{array}$ & $\begin{array}{l}1(10.0) \\
9(90.0)\end{array}$ & $\begin{array}{l}10(6.9) \\
134(93.1)\end{array}$ & 1.000 \\
\hline $\begin{array}{l}\text { Heart Disease } \\
\text { YES } \\
\text { NO }\end{array}$ & $\begin{array}{l}3(1.9) \\
151(98.1)\end{array}$ & $\begin{array}{l}1(10.0) \\
9(90.0)\end{array}$ & $\begin{array}{l}2(1.4) \\
142(98.6)\end{array}$ & 1.000 \\
\hline $\begin{array}{l}\text { Stroke } \\
\text { YES } \\
\text { NO }\end{array}$ & $\begin{array}{l}1(0.6) \\
153(99.4)\end{array}$ & $\begin{array}{l}0(0.0) \\
10(100.0)\end{array}$ & $\begin{array}{l}1(0.7) \\
143(99.3)\end{array}$ & 1.000 \\
\hline $\begin{array}{l}\text { Arthritis } \\
\text { YES } \\
\text { NO }\end{array}$ & $\begin{array}{l}12(7.8) \\
142(92.2)\end{array}$ & $\begin{array}{l}0(0.0) \\
10(100.0)\end{array}$ & $\begin{array}{l}12(8.3) \\
132(91.7)\end{array}$ & 1.000 \\
\hline $\begin{array}{l}\text { Anxiety } \\
\text { YES } \\
\text { NO }\end{array}$ & $\begin{array}{l}7(4.5) \\
147(95.5)\end{array}$ & $\begin{array}{l}0(0.0) \\
10(100.0)\end{array}$ & $\begin{array}{l}7(4.5) \\
137(95.1)\end{array}$ & 1.000 \\
\hline $\begin{array}{l}\text { Asthma } \\
\text { YES } \\
\text { NO }\end{array}$ & $\begin{array}{l}21(13.6) \\
133(86.4)\end{array}$ & $\begin{array}{l}0(0.0) \\
10(100.0)\end{array}$ & $\begin{array}{l}21(14.6) \\
123(85.4)\end{array}$ & 0.359 \\
\hline $\begin{array}{l}\text { Diagnosed other medical conditions } \\
\text { YES } \\
\text { NO }\end{array}$ & $\begin{array}{l}26(16.9) \\
128(83.1)\end{array}$ & $\begin{array}{l}4(40.0) \\
6(60.00\end{array}$ & $\begin{array}{l}22(15.3) \\
122(84.7)\end{array}$ & 0.066 \\
\hline
\end{tabular}

was 1 , nutrition 3 , spiritual growth 4 , interpersonal relationships 3 , and stress management 4.

It is noted that the mode (3) is high, and on average the results indicated that the respondents were neither reporting, nor discussing personal health challenges with health professionals, or pursuing information about improving health.

The mode for physical activity emerges as a 1; although, it is important to note that the respondents were participating in physical activity on a regular basis. However, they were not assessing the impact that the exercise had on their heart rates, nor were they, specifically, planning their activities. The mean for leisure time activity was low, which could be influenced by their definition of leisure time activity, or highlight their cultural differences in the type of activities this questionnaire presented.

On average, the respondents were not consuming the recommended allowance of fruit and vegetables each day, coupled with failing to limit sugar intake, and refusing to follow a prescribed diet plan. This could predispose them to certain health conditions, including obesity. This is an area that the respondents excelled in. In addition, it is important to note that this could be one option, which could be used to cope with the daily challenges experienced.

The mode reflected high for this section; however, the concern was whether the respondents were able to disclose their problems, and/ or whether the relevant human resources were available to them to do so.

The mean for most of these items were reported as low; however, the concern existed that the respondents did not possess adequate stress management skills.

As depicted in figure 1, the majority of the respondents reported not having any medical conditions [60 $(39 \%)]$, while $35.1 \%$ had one medical condition. Fewer respondents [40, $(25.9 \%)]$ reported having more than one medical condition.

\section{Discussion}

It is important to determine the risk factors for NCDs in any population, when planning to implement 
Table 2: Health responsibility responses

\begin{tabular}{|l|l|l|}
\hline BEHAVIOUR & MEAN & MODE \\
\hline $\begin{array}{l}\text { How often do you report signs, or symptoms, to a doctor, or other health professional? } \\
\text { (Report Signs) }\end{array}$ & 2.27 & 3 \\
\hline How often do you read, or watch TV programmes about improving health? (TV) & 2.86 & 3 \\
\hline $\begin{array}{l}\text { How often do you ask health professionals, so that you can understand instructions? } \\
\text { (Instruct) }\end{array}$ & 3.33 & 4 \\
\hline $\begin{array}{l}\text { How often do you get a second opinion, when unsure about your health care provider's } \\
\text { advice? (sec. opinion) }\end{array}$ & 3.07 & 3 \\
\hline $\begin{array}{l}\text { How often do you discuss your health concerns with health professionals? (Concerns } \\
\text { A) }\end{array}$ & 2.88 & 3 \\
\hline $\begin{array}{l}\text { How often do you check your body, at least monthly, for physical changes/danger } \\
\text { signs? (Inspect) }\end{array}$ & 2.73 & 3 \\
\hline $\begin{array}{l}\text { How often do you ask for information from health professionals about how to take good } \\
\text { care of yourself? (Ask) }\end{array}$ & 2.90 & 3 \\
\hline How often do you attend programmes to learn about health care?(Ed Programmes) & 2.65 & 3 \\
\hline How often do you ask for advice, or counselling when you need it? (Guidance) & 3.09 & 3 \\
\hline TOTAL & & 3 \\
\hline
\end{tabular}

Notes: HPLP-II has 52 items, with responses including 1 = never, 2 = Sometimes, 3 = Often, and 4 = Routinely.

Table 3: Physical activity participation

\begin{tabular}{|l|l|l|}
\hline BEHAVIOUR & MEAN & MODE \\
\hline How often do you follow a planned exercise programme? (programme) & 2.08 & 1 \\
\hline $\begin{array}{l}\text { How often do you exercise intensely for 20, or more minutes, at least 3x per week (such } \\
\text { as fast walking, bicycling, dancing)? (Vigorous Exercise) }\end{array}$ & 2.61 & 3 \\
\hline $\begin{array}{l}\text { How often do you participate in light to medium physical activity (such as walking 30-40 } \\
\text { minutes at a time 5 or more times a week)? (Take Part) }\end{array}$ & 3.14 & 4 \\
\hline $\begin{array}{l}\text { How often do you participate in leisure-time (recreational) physical activities (such as } \\
\text { swimming, dancing, bicycling)? (Leisure) }\end{array}$ & 2.15 & 1 \\
\hline How often do you perform stretching exercises at least 3x per week? (Stretch) & 2.26 & 2 \\
\hline $\begin{array}{l}\text { How often do you exercise during usual daily activities (such as walking during lunch, } \\
\text { using stairs, walking)? (Daily Exercise) }\end{array}$ & 3.18 & 4 \\
\hline How often do you check your pulse, when exercising? (Pulse) & 2.14 & 1 \\
\hline How often do you reach your target heart rate, when exercising? (Target) & 2.18 & 1 \\
\hline TOTAL & & 1 \\
\hline
\end{tabular}

Notes: HPLP-II has 52 items, with responses including 1 = never, 2 = Sometimes, 3 = Often, and 4 = Routinely.

Table 4: Nutrition responses of participants

\begin{tabular}{|l|l|l|}
\hline BEHAVIOUR & MEAN & MODE \\
\hline How often do you choose a diet, recommended by my health provider? (Diet) & 2.19 & 3 \\
\hline $\begin{array}{l}\text { How often do you limit the use of sugars and food containing sugar? (sweets) (Sugar } \\
\text { Use) }\end{array}$ & 2.66 & 3 \\
\hline $\begin{array}{l}\text { How often do you ask health professionals, so that you can understand instructions? } \\
\text { (Instruct) }\end{array}$ & 3.33 & 4 \\
\hline How often do you eat 4-5 servings of fruits each day? (Fruit) & 2.38 & 2 \\
\hline How often do you eat 4-5 servings of vegetables each day? (Vegetables) & 2.80 & 3 \\
\hline $\begin{array}{l}\text { How often do you eat 2-3 servings of milk, yoghurt or cheese each day, or as directed } \\
\text { by your healthcare provider? (Dairy) }\end{array}$ & 2.44 & 3 \\
\hline $\begin{array}{l}\text { How often do you eat, at least } 6 \text { or less servings of meat, poultry, fish, dried beans, } \\
\text { eggs, nuts each day, or as directed by your health care provider? (Protein) }\end{array}$ & 2.75 & 3 \\
\hline How often do you read food labels to understand nutrition in packaged food? (Labels) & 3.07 & 4 \\
\hline How often do you eat breakfast? (Breakfast) & 2.85 & 4 \\
\hline TOTAL & & 3 \\
\hline
\end{tabular}

Notes: HPLP-II has 52 items, with responses including $1=$ never, $2=$ Sometimes, $3=$ Often, and $4=$ Routinely. 
Table 5: Participants' responses to spiritual growth

\begin{tabular}{|l|l|l|}
\hline BEHAVIOUR & MEAN & MODE \\
\hline How often do you feel that you are growing and changing in positive ways? (Growing) & 3.02 & 3 \\
\hline How often do you believe that your life has purpose? (Believe) & 3.63 & 4 \\
\hline How often do you look forward to the future? (Future) & 3.62 & 4 \\
\hline How often do you feel happy and at peace with yourself? (Peace) & 3.33 & 4 \\
\hline How often do you work towards long-term goals in your life? (Long term goals) & 3.30 & 4 \\
\hline How often do you find each day interesting and challenging? (Challenges) & 3.25 & 4 \\
\hline How often are you aware of what is important to you in your life? (Important) & 3.43 & 4 \\
\hline How often do you feel connected with some force greater than you? (Connected) & 2.99 & 3 \\
\hline How often do you try new things? (Expose) & 3.36 & 4 \\
\hline TOTAL & & 4 \\
\hline
\end{tabular}

Notes: HPLP-II has 52 items, with responses including $1=$ never, $2=$ Sometimes, $3=$ Often, and $4=$ Routinely.

Table 6: Participants' responses to interpersonal relationships

\begin{tabular}{|l|l|l|}
\hline BEHAVIOUR & MEAN & MODE \\
\hline How often do you discuss problems and concerns with people close to you? (Concerns) & 2.61 & 3 \\
\hline How often do you praise other people easily? (Praise) & 3.44 & 4 \\
\hline How often do you maintain meaningful relationships with others? (Relationships) & 3.53 & 4 \\
\hline How often do you spend time with close friends? (Friends) & 2.99 & 3 \\
\hline How often do you touch, and are you touched by, people you care about? (Touch) & 3.55 & 4 \\
\hline How often do you find ways to meet your needs for intimacy? (Intimacy) & 2.66 & 3 \\
\hline How often do you get support from a group of people, who care about you? (Support) & 2.98 & 3 \\
\hline How often do you settle conflicts through discussion, or give and take? (Conflicts) & 2.99 & 3 \\
\hline TOTAL & & 3 \\
\hline
\end{tabular}

Notes: HPLP-II has 52 items, with responses including 1 = never, 2 = Sometimes, 3 = Often, and 4 = Routinely.

Table 7: Participants' responses to managing stress

\begin{tabular}{|l|l|l|}
\hline BEHAVIOUR & MEAN & MODE \\
\hline How often do you get enough sleep? (Sleep) & 2.83 & 3 \\
\hline How often do you take some time for relaxation each day? (Relax) & 2.92 & 3 \\
\hline How often do you accept those things in your life that you cannot change? (Accept) & 3.27 & 4 \\
\hline How often do you concentrate on pleasant thoughts at bedtime? (concentrate) & 2.97 & 3 \\
\hline How often do you use specific methods to control your stress? (Stress) & 2.55 & 3 \\
\hline How often do you balance time between work and play? (Balance) & 2.74 & 3 \\
\hline How often do you practice relaxation, or meditation, for 15-20 minutes? (Meditation) & 2.23 & 1 \\
\hline How often do you pace yourself, to ensure that you do not become too tired? (Pace) & 2.66 & 3 \\
\hline TOTAL & & 3 \\
\hline
\end{tabular}

Notes: HPLP-II has 52 items, with responses including 1 = never, 2 = Sometimes, 3 = Often, and 4 = Routinely.

\section{No. of Medical Conditions}

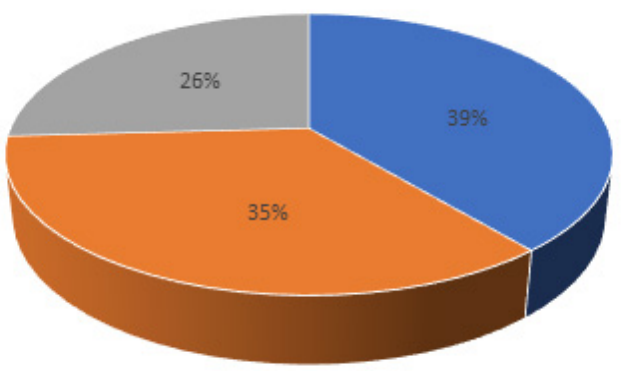


prevention programmes. More importantly, establishing the presence of NCDs in health workers is essential. This current study focused on determining the prevalence of risk factors for NCDs in CHWs. NCDs share common risk factors, such as poor nutrition, excessive use of alcohol, physical inactivity and smoking ${ }^{5}$.

In this current study more than $30 \%$ of the respondents reported hypertension, tobacco use, and physical inactivity. The results of this study are aligned with, and even higher than the findings of other studies. In one study, smoking rates of $11 \%$ among health workers were reported ${ }^{34}$. Recent studies have reported an increase in the use of tobacco in $\mathrm{LMICs}^{35}$, as well as the coloured population, where a $50 \%$ higher mortality rate for coloured smokers has been reported ${ }^{36}$.

Participation in physical activity was observed to be beneficial for the majority of the respondents; however, they did not understand how to monitor the impact of exercise, as well as the health benefits thereof. The results also revealed that the respondents did not have good coping strategies to manage their stress, which highlighted the need for education. Spiritual growth emerged positively among the respondents, which could be perceived as their main coping strategy. However, there is a void in literature regarding the way in which spirituality and spiritual growth could assist CHWs to cope. Although, there is evidence to suggest that strong religious and spiritual affiliations, lead to positive physical and mental health outcomes, as well as improvement in coping skills $\mathrm{s}^{37,38,39}$.

The mean for the concept intimacy was also low, which could be attributed to their lack of understanding of the full concept of intimacy. This was one of the questions that the researcher had to explain, during the completion of the questionnaires, as the respondents were unclear about whether this question referred specially to physically pleasuring their bodies. This uncertainty about the term is understandable as it is referenced in different ways in varying cultures ${ }^{40}$.

It has been reported that the CHW' training and knowledge of risk factors for NCDs is limited and needs drastic improvement ${ }^{23}$, to raise awareness and provide education around modifying lifestyle behaviours ${ }^{41}$. However, this group of respondents presented a low risk profile, in terms of risk factors for NCDs; consequently, it is logical to conclude that, should this group be provided with adequate training, they could be ideally positioned to lead the way in advocating the cessation of smoking ${ }^{35}$, as well as the rehabilitation of other risk behaviours that predispose individuals to NCDs, to the wider society ${ }^{42}$. CHWs are engaged in health promotion and health education activities in communities, to facilitate behaviour change among community members. Therefore, as change agents in communities, CHWs are considered to be the advocates of the health of the general public, ${ }^{43}$ and the role they fulfil in empowering communities with various health promoting activities, is duly acknowledged. ${ }^{44}$

\section{Future Directions}

Future empirical work will be conducted to examine and validate possible cut-off scores for the dimensions of the HPLP-II with respect to health status and health outcomes. This could assist employees to guide the health of CHWs.

\section{Conclusion}

This current study reported that most of the respondents did not engage in health risk behaviours, or have co-morbidities. Their years of experience (mean $=4,5$ years) as CHWs, doing health promotions may have equipped them with knowledge, to understand the risks and consequently, they have been able to implement good health behaviours into their own lives. These characteristics in this cohort of CHWs match the profile of an effective $\mathrm{CHW}$, making them good role models for future deployment, to transfer knowledge and educate communities about good health behaviour practices. Continuous training and health awareness programmes, however, are required to address the needs of those CHWs, who engage in health risk behaviours.

\section{Study Limitations}

Convenience sampling provides us the opportunity to collect data easily but it does not allow for all the findings to be generalised. This however, does not prevent the information to be used as a guide for practice. Another limitation was the inability of the CHWs to understand some questions/ concepts such as "intimacy", "leisure time activity". Furthermore, the sample size is small, raising concerns about the generalization of the findings. Based on the fact that the data were self-reports of prevalence of risk factors, it is subject to recall bias. Despite these limitations, the information can serve as a guide for countries which have a similar context.

\section{Implications of the study}

On an individual level this cohort of CHWs understand the gravity of managing their own health behaviours. This positive example will make them ideal role models to promote good health behaviours and minimise risky health behaviours among the communities they serve. In time these positive lifestyles will assist in eradicating the burden of disease. This information is also useful for the Department of Health who can utilize this data when deciding on the best implementation strategy of CHWs in the primary health care setting to achieve the 2030 healthcare goals and decrease the burden of disease.

\section{References}

1. Republic of South Africa (RSA), National Department of Health (NDoH). Healthcare 2030: The road to wellness. Pretoria, Gauteng, South Africa: Government Printer, 2014. https://www.westerncape. gov.za/assets/departments/health/healthcare2030.pdf.

2. Mohammadnezhad M, Mangum T, May W, Lucas J, Ailson, S. Common modifiable and non-modifiable risk factors of cardiovascular disease (CVD) among pacific countries. World Journal of Cardiovascular Surgery 2016;6(11):153-170. http://dx.doi.org/10.4236/wjcs.2016. 611022.

3. Tabish SA. Lifestyle diseases: Consequences, characteristics, causes and control. J CardiolCurrRes 2017;9(3):00326. http://dx.doi. org/10.15406/jecr.2017.09.00326.

4. Melkamu D, Grace K, Grace J. Perceptions of non-communicable diseases risk factors and its regional distribution in Ethiopia. Global Journal of Health Science 2018;10(1):88. https://doi.org/10.5539/gjhs. v10n1p88.

5. World Health Organization (WHO). Non-communicable diseases. Geneva, Switzerland: WHO, 2018. http://www.who.int/mediacentre/ factsheets/fs355/en/.

6. Khetan A, Zullo M, Rani A, et al. Effect of a community health worker-based approach to integrated cardiovascular risk factor control 
in India. A cluster randomized controlled trial. Global Heart 2019; 14(4): 355-365. https://doi.org/10.1016/ j.gheart.2019.08.003.

7. World Health Organization (WHO). Global action plan for the prevention and control of non-communicable diseases 2013-2020. Geneva, Switzerland: WHO, 2018. https://www.who.int/nmh/events/ ncd_action_plan/en/.

8. South African Medical Research Council (SAMRC). National Burden of Disease Study: SA Medical Research Council briefing, 2017. https://pmg.org.za/committee-meeting/24112/.

9. World Health Organization (WHO). Non-communicable diseases. Country profiles. Geneva, Switzerland: WHO, 2014. https://apps.who. int/iris/bitstream/handle/10665/128038/9789241 507509_eng.pdf;jsess ionid=BF820337537E2F816BABF64F83789423? sequence $=1$.

10. South African Medical Research Council (SAMRC). Second National Burden of Disease Study for South Africa: Cause of death profile - Western Cape Province, 1997-2012. Cape Town, Western Cape Province, South Africa: Medical Research Council, 2016. ISBN:978-1928340-07-2.

11. World Health Organization (WHO). Fact Sheet: Cardiovascular diseases (CVDs). Geneva, Switzerland: WHO, 2016. https://www.who. $\mathrm{int} /$ health-topics/cardiovascular-diseases/\#tab= tab_19.

12. Manning K, Senekal, M, Harbron, J. Non-communicable disease risk factors and treatment preference of obese patients in Cape Town. Afr J Prm Health Care Fam Med.2016;8(1):a913. http://dx.doi. org/10.4102/phcfm.v8il.913.

13. Skaal L, Pengpid S. Obesity and health problems among South African healthcare workers: do healthcare workers take care of themselves? South African Fam Pract [Internet]. 2011 Nov 15;53(6):563-7. Available from: https://www.tandfonline.com/doi/full $/ 10.1080 / 20786204.2011 .10874153$

14. Igumbor EU, Sanders D, Puoane TT, et al. "Big food.". The consumer food environment, health \& the policy response in South Africa. PLOS Med 2012;9(7):e1001253. https://doi.org/10.1371/ journal.pmed.1001253.

15. Sharma S, Anand T, Dey B, Ingle G, Kishore J. Prevalence of modifiable and non-modifiable risk factors and lifestyle disorders among health care professionals. Astrocyte [Internet]. 2014;1(3):178. Available from: http://www.astrocyte.in/text.asp?2014/1/3/178/157757.

16. Joseph J, Joseph M. The health of healthcare workers. Indian J. Occup Environ Med 2016;20(2):71-72. Doi:10.4103/0019-5278.197518.

17. Shisana O, Hall E, Maluleke R, Chauveau J, Schwabe C. HIV/AIDS prevalence among South African health workers [Internet]. Ajol.info. 2004 [cited 6 August 2020]. Available from: https://www.ajol.info/ index.php/samj/article/view/13643.

18. Mazurek JM, Syamlal G. Prevalence of asthma, asthma attacks, and emergency department visits for asthma among working adults National health interview survey, 2011-2016. MMWR. Morb Mortal Wkly Rep2018;67(13):377-386. https://doi.org/10.15585/mmwr. mm6713a1.

19. Metta E, Msambichaka B, Mwangome M, Nyato D, Dieleman M, Haisma $\mathrm{H}$ et al. Public policy, health system, and community actions against illness as platforms for response to NCDs in Tanzania: a narrative review. Global Health Action. 2014;7(1):23439 doi: 10.3402/ gha.v7.23439.

20. 2 million African community health workers [Internet]. Unaids.org. 2020 [cited 5 August 2020]. Available from: https://www.unaids.org/en/ resources/documents/2017/African2mCHW.

21. Tsolekile LP, Puoane T, Schneider H, Levitt NS, Steyn K. The roles of community health workers in management of non-communicable diseases in an urban township. Afr J Prm Health Care Fam Med 2014;6(1):8 pages. https://doi.org/10.4102/phcfm.v6i1.693.

22. Jarvis JD, Kataria I, Murgor M, Mbau M. Community health workers: Underappreciated asset to tackle NCD. Global Heart 2016;11(4)
(201602):455-457. http://doi.org/10.1016/ j.gheart.2016.10.004.

23. Tsolekile LP, Schneider H, Puoane T. The roles, training and knowledge of community health workers about diabetes and hypertension in Khayelitsha, Cape Town. Curationis 2018;41(1):a1815. https://doi.org/10.4102/curationis.v41i1.1815.

24. Kelkar S., Mahapatro M. Community health worker: A tool for community empowerment. Health and Population-Perspectives and Issues 2014;37(1\&2):57-65.

25. Woodall JS, Raine G, South J, Warwick-Booth L. Empowerment and health \& well-being evidence review. Project Report. Centre for Health Promotion Research, Leeds Metropolitan University, 2010. http://eprints.leedsbeckett.ac.uk/2172/.

26. Nardi, Peter M. 2015. Doing Survey Research. 3rd ed. New York, NY 10017, USA: Routledge.

27. Schneider H, Sanders D, Besada D, Daviaud E, Rohde S. Ward-based primary health care outreach teams in South Africa: developments, challenges and future directions. South African Heal Rev. 2018;2018(1):59-65.

28. Languza N, Lushaba T, Magingxa N, Masuku M, Ngubo T. COMMUNITY HEALTH WORKERS - A BRIEF DESCRIPTION OF THE HST EXPERIENCE. Heal Syst Trust [Internet]. 2011;1-8. Available from: https://www.hst.org.za/publications/HST Publications/ CHWs_HSTexp022011.pdf\#search=Health Systems Trust Community Health Workers A Brief Description of the HST Experience.

29. Schopp L, Bike D, Clark M, Minor M. Act healthy: Promoting health behaviours and self-efficacy in the workplace. Advance Access2015;30(4):542-553.

30. Gandek B, Ware JE Jr, Aaronson NK, et al. Cross-validation of item selection and scoring for the SF-12 health survey in nine countries: results from the IQOLA Project. International Quality of Life Assessment. J Clin Epidemiol 1998;51(11):1171-1178.

31. Gandhi SK, Salmon JW, Zhao SZ, Lamberts BL, Gore PR, Conrad $\mathrm{K}$. Psychometric evaluation of the 12-item short-form health survey (SF-12) in osteoarthritis and rheumatoid arthritis clinical trials. Clin Ther 2001;23(7):1080-1098.

32. Obtel M, Rhazi KE, Elhold S, Benjelloune M, Gnatiuc L, Nejjari C. Cross-cultural adaptation of the 12-Item Short-Form survey instrument in a Moroccan representative Survey. Southern African Journal of Epidemiology and Infection2013;28(3):166-171. https://doi.org/10.10 80/10158782.2013.11441540.

33. Hosseini M, Yaghmaei F, Hosseinzade S, AlaviMajd H, Sarbakhsh P, Tavousi M. Psychometric evaluation of the "Health Promoting Life Style Profile 2". Payesh (Health Monitor) [Internet]. 2012 [cited 8 August 2020];11(6):849-856. Available from: http://payeshjournal.ir/ article-1-404-en.html.

34. Okeke PI, Ross AJ, Esterhuizen T, Van Wyk JM. Tobacco and alcohol use among healthcare workers in three public hospitals in KwaZulu- Natal, South Africa. S Afr Fam Pract 2012;54:61-67. Doi: 10.1080/20786204.2012.10874177.

35. Nilan K, McKeever TM, McNeill A, Raw M, Murray RL. Prevalence of tobacco use in healthcare workers: A systematic review and metaanalysis. PLOS ONE 2019;14(7): e0220168. https://doi.org/10.1371/ journal.pone.0220168.

36. Teare JA, Naicker N, Albers P, Mathee A. Prevalence of tobacco use in selected Johannesburg suburbs. S Afr Med J2018;108(1):40-44. https://doi.org/10.7196/SAMJ. 2018.v108i1.12283.

37. Wachholtz AB, Pearce MJ. Does spirituality as a coping mechanism help or hinder coping with chronic pain? Current Science Inc 2009;13:127-132. https://doi-org.ezproxy.uwc.ac.za /10.1007/s11916009-0022-0.

38. Pargament KI, Exline J, Jones J, Mahoney A, Shafranske E. Koenig HG. Role of religion and spirituality in coping with acute and chronic illness. In: APA Handbook of Psychology, Religion and Spirituality. 
Washington, DC., USA: American Psychological Association, 2013 https://scholar-google-com.ezproxy.uwc.ac.za/scholar_lookup?title=A $\mathrm{PA}+$ Handbook + of + Psychology, + Religion + and + Sp irituality\&author $=$ HG+Koegin\&Publication_year $=2013 \&$

39. Koenig HG, King D, Carson V. Handbook of religion and health. New York, NY., USA: Oxford University Press, 2012. https://scholargoogle-com.ezproxy.uwc.ac.za/scholar_lookup?title=Handbook + of $+\mathrm{R}$ eligion + and + Health\&author $=\mathrm{HG}+$ Koenig\&author $=\mathrm{D}+$ King\&author $=$ $\mathrm{V}+$ Carson\&publication_year $=2012 \& .+$ Psychology, + Religion + and + Sp irituality\&author $=$ HG + Koenig\&publication_year $=2013 \&$.

40. Jamieson L. Intimacy as a Concept: Explaining Social Change in the Context of Globalisation or Another Form of Ethnocentricism? Sociol Res Online [Internet]. 2011 Dec 2;16(4):151-63. Available from: http:// journals.sagepub.com/doi/10.5153/sro.2497.

41. Mosha NR, Mahande M, Juma A, et al. Prevalence, awareness and factors associated with hypertension in North West Tanzania. Global Health Action 2017;10(1):1. https://doi.org/10.1080/16549716.2017.1 321279 .
42. Tseng Y, Griffiths F, deKadt J, et al. Integrating community health workers into the formal health system to improve performance: a qualitative study on the role of on-site supervision in the South African programme. BMJ Open 2019;9(2):e022186. https://doi.org/10.1136/ bmjopen-2018-022186.

43. Ahmed MT, Jadhav J, Sobagaiah RT. Assessment of risk factors of non-communicable diseases among healthcare workers in Nelamangala: a cross sectional study. Int J Community Med Public Health 2018;5(2):745-748. Doi:10.18203/2394-6040.ijcmph20180261.

44. Seutloali T, Napoles L, Bam N. Community health workers in Lesotho: Experiences of health promotion activities. Afr J Prm Health Care Fam Med 2018;10(1):a1558. https://doi.org/10.4102/ phcfm. v10i1.1558. 